\title{
The role of Sphingolipids in myelination and myelin stability and their involvement in childhood and adult demyelinating disorders
}

\author{
Paola Giussani (i) | Alessandro Prinetti (D) | Cristina Tringali
}

Department of Medical Biotechnology and Translational Medicine, Università di Milano, LITA Segrate, Segrate, Italy

\section{Correspondence}

Paola Giussani and Cristina Tringali,

Department of Medical Biotechnology and Translational Medicine, Università di Milano, LITA Segrate, Via Fratelli Cervi, 93, 20090 Segrate, Italy.

Email: paola.giussani@unimi.it and cristina. tringali@unimi.it

\section{Funding information}

Piano di sostegno alla ricerca BIOMETRA, Grant/Award Number: - Linea B (grant PSR2018_Giussani) and - Linea B (grant PSR2018_Tringali)

\begin{abstract}
Multiple sclerosis (MS) represents the most common demyelinating disease affecting the central nervous system (CNS) in adults as well as in children. Furthermore, in children, in addition to acquired diseases such as MS, genetically inherited diseases significantly contribute to the incidence of demyelinating disorders. Some genetic defects lead to sphingolipid alterations that are able to elicit neurological symptoms. Sphingolipids are essential for brain development, and their aberrant functionality may thus contribute to demyelinating diseases such as MS. In particular, sphingolipidoses caused by deficits of sphingolipid-metabolizing enzymes, are often associated with demyelination. Sphingolipids are not only structural molecules but also bioactive molecules involved in the regulation of cellular events such as development of the nervous system, myelination and maintenance of myelin stability. Changes in the sphingolipid metabolism deeply affect plasma membrane organization. Thus, changes in myelin sphingolipid composition might crucially contribute to the phenotype of diseases characterized by demyelinalization. Here, we review key features of several sphingolipids such as ceramide/dihydroceramide, sphingosine/dihydrosphingosine, glucosylceramide and, galactosylceramide which act in myelin formation during rat brain development and in human brain demyelination during the pathogenesis of MS, suggesting that this knowledge could be useful in identifying targets for possible therapies.
\end{abstract}

\section{KEYWORDS}

demyelination, multiple sclerosis, myelin, sphingolipidoses, sphingolipids

\section{1 | INTRODUCTION}

Demyelinating diseases affect both adults and children and encompass a large spectrum of disorders caused by different mechanisms including abnormal autoimmune or inflammatory responses, viral infections, metabolic alterations, genetic defects, etc.
In adults, multiple sclerosis (MS) represents the most common demyelinating disease affecting the central nervous system (CNS). Its prevalence is about $50-300$ per 100,000 people (Thompson, Baranzini, Geurts, Hemmer, \& Ciccarelli, 2018). Despite the great efforts in research devoted to this field, the aetiology of the disease is intricate and is not still fully understood in all its relevant facets. 
Genetic, epigenetic and environmental factors, including vitamin D deficiency, Epstein-Barr virus infection, UVB exposure, smoke appear to be implicated, but the cause, or, possibly more correctly, the mix of causes, specifically inducing the disease need to be identified (Dobson \& Giovannoni, 2019). Pathogenic injuries of MS typically consist of oligodendrocyte loss and extensive demyelination, which in magnetic resonance imaging (MRI) appears as lesions, better known as plaques, in the white and grey matter. A marked inflammatory response with infiltrating $T$ and $B$ lymphocytes characterizes demyelinated areas, along with the activation of astrocytes. Even if inflammation is considered a hallmark of MS, currently it seems reasonable to assume that it is not the only cause of demyelination and oligodendrocyte decay (Lassmann, 2018). Demyelination damage can be partially reverted by oligodendrocyte progenitor cells. Because of their functioning, MS progression is heterogeneously varying from relapsing forms to a progressive phenotype during which neurodegeneration prevails (Lassmann, 2018).

In children, in addition to acquired diseases, particularly MS, transverse myelitis, optic neuritis, acute disseminated encephalomyelitis, neuromyelitis optica, genetically inherited diseases significantly Contribute to developing demyelinating disorders. Even if these latter types of disease are generally considered rare, a study performed in the Washington DC metropolitan area reported that their cumulated incidence is fairly comparable to that of acquired demyelinating diseases during childhood (Vanderver, Hussey, Schmidt, Pastor, \& Hoffman, 2012). Among the heritable demyelinating diseases are some sphingolipidoses. Sphingolipidoses constitute a category of lysosomal storage diseases where substrate accumulation is primarily because of genetic mutations leading to severe deficiency of glycohydrolytic enzymes involved in sphingolipid catabolism (Grassi, Chiricozzi, Mauri, Sonnino, \& Prinetti, 2019). Of note, also genetic defects concerning sphingolipid synthesis have been described recently and were traced back to a novel class of inherited diseases (Lamari, Mochel, Sedel, \& Saudubray, 2013).

Sphingolipids originate from the coupling of a hydrophobic molecule, the ceramide-in turn formed by the $18 \mathrm{C}$ amino alcoho sphingosine linked to a fatty acid-with hydrophilic molecules such as monosaccharides, oligosaccharides or phosphocholine. This peculiar chemical structure makes sphingolipids ideal constituents of the plasma membranes where they are inserted through the hydrophobic portion. In contrast, the hydrophilic groups are exposed in the extracellular milieu and are involved in cell-cell or cell-extracellular matrix interactions; on the other hand, they can establish lateral cis contacts with other plasma membranes components such as receptors and integrins. The CNS is particularly enriched with sphingolipids that are pivotal components of the myelin sheath or of the plasma membranes of resident cells where they modulate processes such as signal transduction, apoptosis, autophagy, senescence, necrosis and differentiation (Giussani, Tringali, Riboni, Viani, \& Venerando, 2014). Ceramide levels are directly interconnected with sphingosine 1-phosphate (S1P) and both these molecules act in signal transduction. Based on these premises, it is not surprising that genetic defects leading to sphingolipid alterations can strongly affect CNS, and elicit neurological symptoms. Sphingolipidoses summarized in Table 1 are characterized by demyelination. All of them are transmitted following the autosomal recessive way, with the exception of Fabry's disease that is X-linked inherited.

It is well-known that MS phenotype can share some peculiarities with several single-gene disorders, specifically, the presence of white matter lesions detectable by MRI (Weisfeld-Adams, Katz Sand, Honce, \& Lublin, 2015). Episodes of misdiagnosis have been reported, above all with Fabry's disease (Colomba et al., 2018; Yau, Fabis-Pedrini, \& Kermode, 2017) and adult-type metachromatic leukodystrophy (Chebel et al., 2009). A diagnostic problematic exists in particular with late manifestation of symptoms because of rare genetic diseases, during adolescence. Can we assume that the connection between MS and genetic disorders consists only of similar phenotypical tracts or symptoms? Both older and recent evidence from studies tackling Gaucher's and Parkinson's diseases (Migdalska-Richards \& Schapira, 2016) implies that this could not be the case. Emerging data highlight dysfunctional similitudes and common genetic variants between MS and inborn sphingolipidoses. These findings could significantly contribute to better elucidate the pathogenesis and aetiology of MS and, possibly, to trace the way to find novel markers able to identify at-risk subjects. Moreover, even if the incidence of sphingolipidoses is low, it must be taken in account that the frequency of heterozygous alleles is quite high and therefore, if there is a link with adult demyelinating disorders, their impact can be significant.

\section{2 | COMMON GENETIC ALTERATIONS AMONG MS AND INBORN SPHINGOLIPIDOSES}

Heterozygous carriers of genetic variants associated with the appearance of sphingolipidoses, with one wild-type allele, are typically considered healthy. However, polymorphisms affecting the same genes are frequently expressed in disorders affecting adults (Indellicato \& Trinchera, 2019). Pioneering studies recognized a straightforward connection between Gaucher's disease and Parkinson's disease in the late ' 80 (Migdalska-Richards \& Schapira, 2016). By now, it is well established that mutations occurring in the GBA1 gene coding for the glucocerebrosidase 1, involved in Gaucher's disease, represent a significant risk factor for Parkinson's disease also when inherited in a heterozygous state (Migdalska-Richards \& Schapira, 2016). Furthermore, it appears increasingly conceivable that mutations affecting sphingolipids metabolizing enzymes could be related to different types of neuro-disorders.

MS is not a classic genetic disease. However, the involvement of genetic predisposition is well documented. The risk of developing MS ranges around $25 \%-30 \%$ in monozygotic twins, and between $3 \%$ and $7 \%$ in dizygotic twins (Dyment, Sadovnick, \& Ebers, 1997). Moreover, a familiar occurrence has been recorded in $15 \%-20 \%$ of patients (Compston \& Coles, 2002). The human leucocyte antigen (HLA) mapped on chromosome 6 p21.3 is undoubtedly the locus 
with the strongest association with MS; other genes unrelated to this locus have been identified in MS. More than 200 common variants related to MS risk have been identified through numerous genome-wide association studies (GWAS) (Australia and New Zealand Multiple Sclerosis Genetics Consortium (ANZgene), 2009; Baranzini et al., 2009; De Jager et al., 2009; Jakkula et al., 2010; MartinelliBoneschi et al., 2012; Patsopoulos, Esposito, \& Reischl, 2011; Baranzini \& Oksenberg, 2017; Sawcer et al., 2011; Beecham et al., 2013). Also rare variants (MAF < 5\%) contribute to MS risk (International Multiple Sclerosis Genetics Consortium, 2018). The majority of these genes are involved in immune response regulation and in signalling pathways modulating immune cells homeostasis, confirming that intrinsically, MS is an autoimmune disorder.

Some studies analysed the occurrence of genetic variants involved in single-gene diseases with classical Mendelian inheritance showing MS clinical and radiological hallmarks (Traboulsee et al., 2017). Recurrent mutations affecting CYP27A1 (cytochrome P450 oxidase), LYST (lysosomal trafficking regulator), PDHA1 (pyruvate dehydrogenase E1 component subunit alpha), CLCN2 (chloride channel), GALC (galactocerebrosidase) and POLG (DNA polymerase gamma subunit) were identified (Traboulsee et al., 2017).

The rs794185 SUMF1 (sulphatase-modifying factor 1) variant has been associated with high levels of cerebral glutamate and strong neurodegeneration in MS patients (Baranzini et al., 2010). SUMF1 encodes an enzyme involved in post-translational modification and activation of sulphatases. SUMF1 mutations are responsible for multiple sulphatase deficiency (MSD) and metachromatic leukodystrophy onset. MSD, or mucosulphatidososis, is characterized by the simultaneous enzymatic deficit of sulphatases because of the impossibility to oxidase a cysteine residue into the consensus sequence CysXProXArg that is common to all sulphatases and pivotal to their enzymatic activity (Laquerriere, Bekri, Suzuki, \& Harding, 2018). The disease induces accumulation of sulphatides, mucopolysaccharides and steroid sulphates, gangliosides, and is characterized by neurological involvement and white matter degeneration detectable with MRI (Table 1).

GALC, the gene involved in the pathogenesis of Krabbe's disease, has been identified by GWAS studies as a locus strongly involved in the risk for MS, even if it is not involved in immune response (Sawcer, Franklin, \& Ban, 2014; Sawcer et al., 2011; Traboulsee et al., 2017). Also, GALC variants have been related to synucleinophaties (Marshall \& Bongarzone, 2016). Galactosylceramide (GalCer) is the main component of myelin and its turnover is ensured by the lysosomal enzyme galactocerebrosidase (GALC). GALC is able to act after forming a heterotetramer with saposin A (Sap A), that occurs at pH 5-6 (Hill et al., 2018). GALC deficiency above 90\%, triggered by the presence of two mutated alleles, is responsible for the appearance of Krabbe's or globoid-cell leukodystrophy. Krabbe's disease affects mainly children (3-6 months) and less frequently adolescents or adults. Histological features of Krabbe's patients are neurodegeneration along with large areas of demyelination with loss of oligodendrocytes, gliosis and the appearance of the so-called globoid cells that are microglia/macrophages engulfed of undigested material.
Characteristically, the molecule that is accumulated in the brain of Krabbe's patients is psychosine, that is galactosylsphingosine that is produced by the galactosylation of sphingosine by UDP-galactose ceramide galactosyltransferase (Cleland \& Kennedy, 1960) or by the deacylation of GalCer by acid ceramidase (Li et al., 2019). In any case, GALC deficiency impairs psychosine catabolism provoking its accumulation that is deeply toxic for oligodendrocytes and also for neurons. Over 100 mutations affecting GALC, that spans $60.2 \mathrm{~kb}$, have been discovered; in Europe, the most common is a $30 \mathrm{~kb}$ deletion mapped from 11th to 17th exon (502T/del) (Laquerriere et al., 2018). Different mutations affect GALC functionality in different way: by impairing the conformation of the catalytic site, by altering the enzyme folding, processing or localization, or by distorting its ability to associate with coactivators (Spratley et al., 2016). As outlined, the pathogenesis of Krabbe's disease has been closely linked historically to psychosine accumulation (Igisu \& Suzuki, 1984). Also, nowadays, it is undeniable the toxicity exerted by this molecule that, among numerous effects, disrupts membrane lipid raft organization (White et al., 2009), modifies plasma membrane fluidity and shedding (D'Auria et al., 2017), activates phospholipase A2, inducing oligodendrocyte death (Giri, Khan, Rattan, Singh, \& Singh, 2006). However, based on current evidence, it is difficult to fully explain the Krabbe's leukodystrophy phenotype on the basis of psychosine only, let alone during the disease's early phases. Down-regulation of GALC co-orthologs in Zebrafish (Danio rerio) causes severe impairment of CNS development, even if psychosine levels remain undetectable (Zizioli et al., 2014). In GaLCtwi-5J homozygotic mice that spontaneously harbour the same mutation identified in a group of affected children, it became evident that the correlation between psychosine levels and the severity of dysfunctions including demyelination is not so unequivocal (Potter et al., 2013). It was thus hypothesized that GALC deficits impacted the CNS and its resident cells also through different mechanisms in addition to psychosine. This could at least in part explain why GALC represents a major risk locus for MS. As outlined, Krabbe's disease manifests when two copies of mutated alleles are inherited, an event that occurs with an incidence of 1:100,000-200,000 births. The carrier frequency is $1: 150$ (Laquerriere et al., 2018). GALC \pm animals have been demonstrated to be clinically similar to WT animals at 3 months of age, exhibiting no accumulation of psychosine. Also, the response of twitcher GALC \pm animals to cuprizone exposure was analogous to that of WT animals, resulting in oligodendrocyte loss and demyelination in corpus callosum. But after cuprizone removal, in GALC \pm animals a clear defect in remyelination appeared (Scott-Hewitt et al., 2017). The authors of that study recognized a defect in the capability of microglia of increasing Trem2 and removing myelin debris (Scott-Hewitt et al., 2017) and suggested a link to MS progression (Scott-Hewitt, Folts, \& Noble, 2018).

ARSA gene encodes the lysosomal enzyme arylsulphatase A (ASA) that is responsible for the catabolism of 3-O-sulphogalactosylceramides or sulphatides to form GalCer (Takahashi \& Suzuki, 2012). In the nervous system, sulphatides are particularly produced by oligodendrocytes (and by Schwann 
cells in the periphery) and are constituents of myelin (Takahashi \& Suzuki, 2012). Genetic mutations of ARSA or of saposin B, that acts as coactivator, leading to ASA deficiency are well recognized as the causal mechanism of metachromatic leukodystrophy, a frequently fatal disease, prevalently with an infantile onset, characterized by a progressive and diffuse demyelination of CNS and peripheral nervous system (PNS) (Laquerriere et al., 2018). Strangely, polymorphisms leading to ASA deficiency has been found also in healthy subjects, without symptoms of leukodystrophy. This condition is designated an ASA pseudodeficiency, and its frequency is about $15 \%$ in the total population (Herz \& Bach, 1984). In the past, it has been hypothesized that these polymorphisms might be associated with MS (Kappler et al., 1991). Other than that, it has been demonstrated that MS patients carrying ASA pseudodeficiency polymorphisms showed a more severe clinical phenotype, ascertained by the employment of the expanded disability status scale (EDSS), MS severity score (MSSS) and MRI (Baronica, Mlinac, Ozretić, Vladić, \& Bognar, 2011).

\section{3 | ALTERATION OF SPHINGOLIPID METABOLISM IN MS}

Sphingolipidoses are primarily characterized by the accumulation of substrates that cannot be degraded because of the existence of a genetic defect (Figure 1). In addition, other secondary sphingolipid alterations, likewise not directly linked to the primary enzymatic deficiency, have been described (Prinetti et al., 2011; Walkley, 2004). These alterations could be potentially related to signalling dysfunctions that can worse disease progression because of the role played by sphingolipids in signalling and plasma membrane organization.

The relationship between MS and sphingolipids/sphingoid molecules is intriguing as Fingolimod, FTY720, the first drug approved for immunomodulation in relapsing-remitting $\mathrm{MS}$ is a modulator of sphingosine-1-phosphate (S1P) receptor. The efficacy of this drug is because of its capability to down-regulate S1P signalling and to prevent lymphocytes motility toward CNS reducing the autoimmune and inflammatory responses (Chun \& Hartung, 2010).

In MS pathogenesis, sphingolipids are plausibly involved in the autoimmune response. In fact, anti-ganglioside antibodies are largely present in MS patients. Their presence has been known for decades (Arnon et al., 1980). Furthermore, antibodies against GD2-like antigens (Marconi et al., 2006), sulphatide, sphingomyelin (SM) (Kanter et al., 2006), GM3, GQ1b (Pender et al., 2003), GD1a (Matà, Lolli, Söderström, Pinto, \& Link, 1999), GM4, GM1 and galactocerebroside have been detected (Kasai, Pachner, \& $\mathrm{Yu}, 1986)$. Other dysfunctions concerned sphingolipid metabolism. In 1968, the existence of a modified cerebroside/sulphatide ratio in the white matter of MS patients has been described (Cumings \& Goodwin, 1968; Halmer, Walter, \& Faßbender, 2014) and, fairly concomitantly, a high content of sphingosine (Sph) has been recorded (Moscatelli \& Isaacson, 1969). Many years later, in 2000, Marbois and coworkers were able to demonstrate reduced sulphatide content, contrasted by an increased hydroxylated sulphatide content (Marbois, Faull, Fluharty, Raval-Fernandes, \& Rome, 2000); whereas in 2008, Wheeler and coworkers found that in normal appearing white and grey matter taken from MS

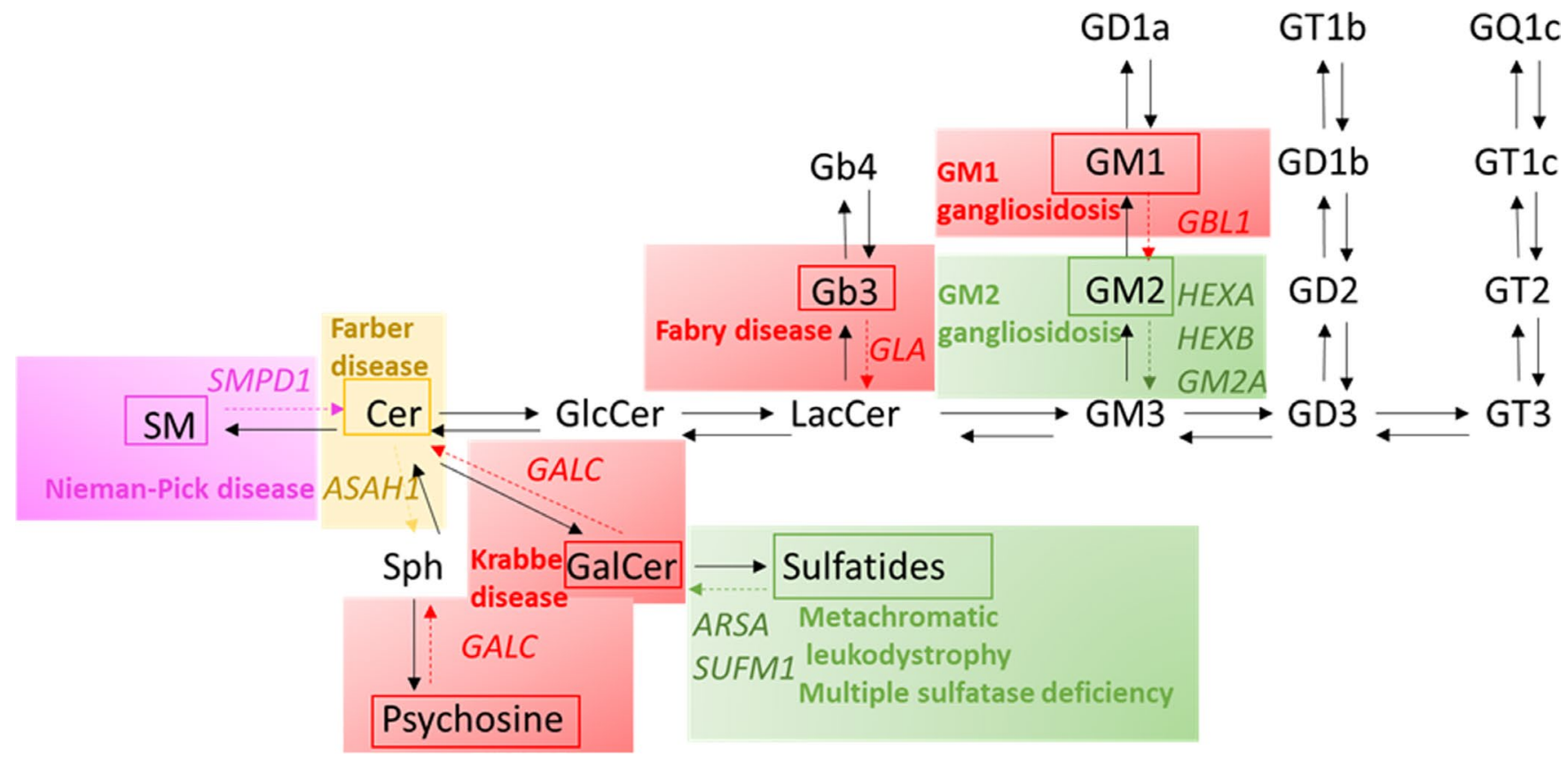

FIGURE 1 Sphingolipid catabolism alterations in demyelinating sphingolipidoses Sphingolipid catabolic pathways are depicted from complex sphingolipids to sphingosine. Gene alterations associated with metabolic disorders are evidenced by colour squares along with their accumulated substrates. SM: sphingomyelin; Cer: Ceramide; Sph: sphingosine; GalCer: galactosylceramide; GlcCer: glucosylceramide; LacCer: lactosylceramide; Gb3: globotryaosylceramide; Gb4: globoside 
patients there was a higher phospholipid/sphingolipid ratio than normal (Wheeler, Bandaru, Calabresi, Nath, \& Haughey, 2008). As mentioned, reduced brain sulphatide levels are a common finding in plaques and in normal appearing white matter in MS patients (Marbois et al., 2000; Yahara, Kawamura, Kishimoto, Saida, \& Tourtellotte, 1982). Increased sulphatide levels were not only detected in serum (Moyano et al., 2013) and cerebrospinal fluid (CSF) from patients (Haghighi, Lekman, Nilsson, Blomqvist, \& Andersen, 2012) but also in their healthy siblings (Haghighi, Lekman, Nilsson, Blomqvist, \& Andersen, 2013), suggesting that it might represent a risk factor and/or a prognostic clue rather than simply being the obvious consequence of the myelin lesion. On the other hand, the presence of anti-sulphatide antibodies in serum is a common finding in MS patients (Haghighi et al., 2012, 2013; Ilyas, Chen, \& Cook, 2003; Podbielska \& Hogan, 2009). Since sulphatides deeply affect the functions of immune system cells within the CNS (Halder, Jahng, Maricic, \& Kumar, 2007; Jeon, Yoon, Park, Kim, \& Park, 2008; Maricic, Halder, Bischof, \& Kumar, 2014; Mycko et al., 2014), anti-sulphatide antibodies might be responsible for worsening the conditions of myelin-producing cells in this disease.

Ceramide (Cer) content is higher in areas around plaques (Singh, Pahan, Khan, \& Singh, 1998) and in cerebrospinal fluid (CSF) of MS patients (Vidaurre et al., 2014). Cer levels are modulated through the so-called 'SM pathway', by sphingomyelinases (SMase), enzymes that can be activated through the signalling cascades triggered by proinflammatory cytokines such as TNF $\alpha$ (Jana \& Pahan, 2010). SM content is decreased, whereas acid SMase is greatly released through exosome-cargos in CSF of MS patients (Pieragostino et al., 2018). Generation of Cer by the acid SMase seems to be an important trigger in the pathology. Treatment of mixed glial cultures with the remyelination-promoting antibody rHIgM22 (Watzlawik, Warrington, \& Rodriguez, 2013) was able to reduce the activity of acid SMase, preventing Cer generation and subsequent apoptosis in mouse brain and cultured oligodendrocytes (Chudakova et al., 2008). Moreover, genetic or pharmacological inhibition of acid SMase reduced clinical symptoms and inflammation in experimental autoimmune encephalomyelitis (EAE) mice, that is the animal model used for MS (Askari, Baradaran Rahimi, Tab atabaee, \& Shafiee-Nick, 2019; Becker et al., 2017; Walter et al., 2019). Acid SMase modulation can favour myelin repair, as reported by Chami and coworkers, who reported that, after demyelination induced by cuprizone, in acid SMase-deficient mice models, oligodendrocytes increased, and myelin repair occurred faster than in wild-type controls (Chami et al., 2017). However, the potential use of acid SMase as a potential biomarker for MS activity and progression is still under debate (Leurs et al., 2019). Intriguingly, acid SMase deficiency because of genetic defects affecting the SMPD1 gene is the hallmark of Niemann-Pick disease types A (total enzyme deficiency) and B (around $10 \%$ residual enzyme activity). Accumulation of SM and cholesterol lead to neuron death which manifests as a severe neurodegeneration in Niemann-Pick type A. In type B, by contrast, neurological involvement is absent or negligible in the majority of subjects (Schuchman, 2007).
In sera specimens of relapsing-remitting MS patients an increased content of GM1 and GD1a was described during the first presentation of the disease, whereas during relapse GM1 decreased and GD1a maintained elevated (Zaprianova et al., 2001). Lactosylceramide (LacCer) was found at higher levels in CNS of EAE mice and in CNS MS lesions, an event that was related to microglia, monocyte and astrocyte activation in addition to neurodegeneration (Mayo et al., 2014). Lysosomes represent the pivotal cellular centre where sphingolipid catabolism occurs. Evidences reporting lysosome dysfunction in MS are few, but significant. In 1979, a fragility of lysosomes in MS white matter was reported (McKeown \& Allen, 1979).

\section{4 | THE ROLE OF SPHINGOLIPIDS IN MYELINATION}

Sphingolipids and their metabolic machinery are fundamental characteristics of all eukaryotic cells (Clarke et al., 2019; Merrill, 2011). In fact, this metabolic pathway is necessary to produce: (1) bioactive sphingolipids (such as Cer, Sph and S1P) involved in the regulation of cell fate including the regulation of cell growth and death; (2) complex sphingolipids such as SM and glycosphingolipids that are necessary for the membrane structure and functional organization.

Sphingolipids are enriched in the CNS and are associated with many biological functions. They seem to play an active role in tissue development, cell recognition and adhesion, and they are also able to act as receptors for toxins (Dasgupta \& Ray, 2017). In particular, specific glycosphingolipis have unique properties essential for their physiological function in forming the tightly packed myelin membrane necessary to isolate neuronal axon (Clarke et al., 2019; Dunn, Tifft, \& Proia, 2019). Myelin is abundantly enriched in lipids, particularly cholesterol and sphingolipids. The correct metabolism and supply of these molecules are crucial for the maintenance of physiological functions of the brain and for the development of the nervous system. The altered metabolism of cholesterol and sphingolipids is often associated with neurodegenerative diseases (Hussain et al., 2019).

The myelin sheaths, which are lipid-rich, multilamellar membrane stacks and are produced by oligodendrocytes, are crucial for electric insulation and viability of neurons. The protein and lipid composition of myelin is very peculiar. In fact, the lipid composition of myelin varies significantly from other biological membranes. The sphingolipids are highly abundant and their metabolism is finely tuned; the enzymes involved have different subcellular regulation and, subsequently, the inter-organelle transport can be a point of regulation for metabolic destiny of sphingolipid precursors. It would be very important to understand the regulation of sphingolipid metabolism in myelin formation to treat demyelinating diseases (Wattenberg, 2019).

Sphingolipids are recognized not only as structural molecules but also as regulators of cellular events, for example through the 
formation of membrane microdomains. Such compartmentalization is involved in pivotal mechanisms such as myelin stability (Grassi et al., 2020). Increasing evidence implies that microdomains are very heterogeneous, often depending on the sphingolipid variety. Changes in the sphingolipid metabolism can lead to plasma membrane rearrangements that can be responsible for numerous neurological diseases (Olsen \& Færgeman, 2017). On these bases it can be hypothesized that changes in myelin sphingolipid composition are key to study diseases characterized by demyelinalization.

During the myelinization process, molecules from different origins (not only lipids but also proteins) participate to this mechanism. Among these molecules, the specific role of some sphingolipids is yet unclear. Several sphingolipids (Cer/dihydroceramide, Sph/dihydrosphingosine, glucosylceramide (GlcCer) and, GalCer) are involved in myelin formation during rat brain development and in human brain demyelination during the pathogenesis of MS (Dasgupta \& Ray, 2017). The obtained results implied that sphingolipids are essential for brain development, but at the same time, they are involved in demyelinating diseases such, for example MS; sphingolipids levels change during rat brain development and have a specific profile even if their specific roles have not been specified yet (Dasgupta \& Ray, 2017).

\section{1 | Cer, dihydroceramide and Sph}

Cer and dihydroceramide levels increase during rat brain development and subsequently decrease until maturity; GlcCer in creases in the first part of brain development and then during the advanced stages, GalCer increases; Sph and dihydrosphingosine levels increase during the first part of the development and then remain at lower levels. Furthermore, a study by Schmitt et al demonstrated that, in mice mutated for different lipid biosynthesis pathways, glial cells involved in myelination have the capacity to overcome the lack of single lipids even if this compensation does not work in maintaining long-term stability of myelin (Schmitt, Castelvetri, \& Simons, 2015).

On the other hand, (1) Cer is involved in neurodegenerative diseases such as Alzheimer's disease and Parkinson's disease; (2) Sph, that has been demonstrated as a protein kinase $C$ inhibitor (Hannun \& Bell, 1989), is implicated in demyelination in MS (Dasgupta \& Ray, 2017); (3) inflammatory cytokines stimulate Sph increase inducing oligodendrocytes death and causing demyelination.

The mammalian ORMDL proteins (ORMDL1, 2 and 3) are involved in the regulatory mechanisms that control sphingolipid levels. In particular, they inhibit serine palmitoyl transferase in response to elevated Cer levels; with this mechanism they mediate feedback inhibition of the de novo sphingolipid synthesis. Clarke et al, using ORMDL genes knockout mice demonstrated that ORMDLs are essentials to control the de novo sphingolipid biosynthetic pathway and to guarantee a correct myelination process (Clarke et al., 2019).

\section{2 | Sphingosine-1-phosphate}

Various studies (Coelho, Saini, \& Sato-Bigbee, 2010; Saini et al., 2005) discovered that S1P can exert its action at different stages of maturation of oligodendrocytes. S1P can exert direct action or can interact with signalling of neurotrophin-3 and PDGF (Coelho et al., 2010; Saini et al., 2005) during oligodendrocyte maturation and myelination process. Recently, it has been demonstrated that S1P in extracellular vesicles produced by microglia, stimulates oligodendrocyte precursor cells migration, that is the first step in myelin repair (Lombardi et al., 2019).

S1P can act as an extracellular as well as an intracellular mediator. Extracellular S1P exerts its effects through specific receptors at the plasma membranes $\left(\mathrm{S}_{1} \mathrm{P}_{1-5}\right.$ ) (Giussani et al., 2014; Grassi, Mauri, et al., 2019). Different studies evaluated the role of S1P receptors in oligodendrocytes maturation and myelination process. Dukala et al demonstrated that $\mathrm{S}_{1} \mathrm{P}_{1}$ deletion in oligodendrocytes induced mild abnormalities in myelin even if it did not significantly modified the number of oligodendrocytes (Dukala \& Soliven, 2016). In a different study it has been found that $\mathrm{S}_{1} \mathrm{P}_{1}$ downstream signalling regulates oligodendrocyte maturation and myelination process (Dukala \& Soliven, 2016; Pyne \& Pyne, 2017). In fact, S1P $_{1}$ deficiency induces slower differentiation of oligodendrocyte precursors (Dukala \& Soliven, 2016; Pyne \& Pyne, 2017), associated with a decrease of myelin basic protein levels and reduced myelin thickness in the corpus

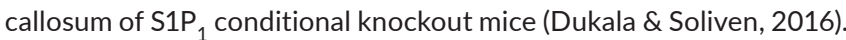
Different studies demonstrated that FTY720-p (an inhibitor of S1P receptors), in vitro, regulates the differentiation and survival of oligodendrocytes (Coelho, Payne, Bittman, Spiegel, \& Sato-Bigbee, 2007; Dukala \& Soliven, 2016; Jung et al., 2007; Miron, Hall, Kennedy, Soliven, \& Antel, 2008; Miron, Jung, et al., 2008). Furthermore, FTY720 supports remyelination (Bigaud, Guerini, Billich, Bassilana, \& Brinkmann, 2014; Pyne \& Pyne, 2017). Moreover, Dukala and coworkers published results demonstrating that FTY720 treatment of mice protects oligodendrocytes from cuprizone damage. This protective effect from demyelination is not only promoted by the direct effect of S1P through its receptors but also by anti-inflammatory effects on astrocytes and microglia (Dukala \& Soliven, 2016; Kim et al., 2011).

Furthermore, a recent paper by Seyedsadra and coworkers investigated the role of the $\mathrm{S} 1 \mathrm{P}$ receptor $\mathrm{S}_{2} \mathrm{P}_{2}$ in myelin repair and demyelination process. The authors demonstrated a negative role of $\mathrm{S}_{1} \mathrm{P}_{2}$ in myelin repair; in fact, $\mathrm{S}_{2} \mathrm{P}_{2}$ pharmacological inactivation or gene knockdown is associated with increased myelin repair (Seyedsadr et al., 2019). Moreover, $\mathrm{S}_{1} \mathrm{P}_{2}$ inactivation decreased blood-brain leakage, suggesting a critical role of this S1P receptor in demyelinization through the regulation of blood-brain barrier permeability (Seyedsadr et al., 2019).

\section{3 | Sulphatides and gangliosides}

Gangliosides and sulphatides are membrane glycosphingolipids with a crucial role in maintaining nervous system integrity. 
TAB LE 1 Sphingolipidoses characterized by demyelination (data from Laquerriere et al., 2018)

\begin{tabular}{|c|c|c|c|}
\hline Pathology & Inheritance & Genetic defect & Enzymatic deficiency \\
\hline GM1 gangliosidosis (MIM 230,500) & Autosomal recessive & GBL1 (3p21.33) & $\beta$ galactosidase \\
\hline $\begin{array}{l}\text { GM2 gangliosidosis } \\
\text { (MIM 268,800) } \\
\text { (MIM 272,750) }\end{array}$ & Autosomal recessive & $\begin{array}{l}\text { HEXA (15q23) } \\
\text { HEXB (5q13) } \\
\text { GM2A (5q33) }\end{array}$ & $\begin{array}{l}\beta \text { hexosaminidase } \\
\text { GM2 activator }\end{array}$ \\
\hline $\begin{array}{l}\text { Fabry's disease } \\
\text { (MIM 301,500) }\end{array}$ & X-linked recessive & GLA (Xq22.1) & $\alpha$ galactosidase \\
\hline $\begin{array}{l}\text { Metachromatic leukodystrophy } \\
\text { (MIM 250,100) }\end{array}$ & Autosomal recessive & $\operatorname{ARSA}(22 q 13)$ & arylsulphatase \\
\hline $\begin{array}{l}\text { Multiple sulphatase deficiency } \\
\text { (MIM 272,200) }\end{array}$ & Autosomal recessive & SUFM1 (13p26) & Formylglycine generating enzyme \\
\hline $\begin{array}{l}\text { Krabbe's disease } \\
\text { (MIM 245,200) }\end{array}$ & Autosomal recessive & GALC (14q31) & Galactosylceramidase \\
\hline $\begin{array}{l}\text { Niemann-Pick type A } \\
\text { (MIM 257,200) }\end{array}$ & Autosomal recessive & SMPD1 (11p15.1-p15.4) & Acid sphingomyelinase \\
\hline $\begin{array}{l}\text { Niemann-Pick type C } \\
\text { (MIM 257,220) }\end{array}$ & Autosomal recessive & $\begin{array}{l}\text { NPC1 (18q11.q12) } \\
\text { NPC2 (14q24) }\end{array}$ & $\begin{array}{l}\text { NPC intracellular cholesterol } \\
\text { transporter } 1 \\
\text { NPC intracellular cholesterol } \\
\text { transporter } 2\end{array}$ \\
\hline $\begin{array}{l}\text { Farber's disease } \\
\text { (MIM 228,000) }\end{array}$ & Autosomal recessive & ASAH1 (8p22-22.1) & $N$-acylsphingosine deacylase \\
\hline
\end{tabular}

Microdomains, that contains both sulphatides and gangliosides, are necessary to correctly localize and make specific proteins work. Only the double, but not the single, deficiency of sulphatides and gangliosides is associated with a lethal phenotype in early age (Ishibashi et al., 2002; McGonigal et al., 2019). Gangliosides and sulphatides, that are associated with rafts, are crucial in maintaining myelin integrity. In fact, in early life as well in age-dependent neurodegeneration, mice deficient in cerebroside sulphotransferase or _-1,4- $\mathrm{N}$-acetylgalactosaminyltransferase 1 are characterized by disorganization of proteins at the node of Ranvier (Ishibashi et al., 2002; McGonigal et al., 2019). Sulphatides are mainly expressed and functional in glial membranes, whereas gangliosides in neurons. It is suggested that these glycosphingolipids stabilize proteins at the axonal glial junction (Ishibashi et al., 2002; McGonigal et al., 2019). Furthermore, brain gangliosides, GD1a and GT1b in particular, establish functional interactions with the myelin-associated glycoprotein (MAG), a lectin binding the sequence 'NeuAc alpha 3Gal beta 3GalNAc', that controls myelin stability and nerve regeneration. Mice models which cannot express 'NeuAc alpha 3Gal beta 3GalNAc' showed extensive demyelination and neurodegeneration (Vyas et al., 2002; Vyas \& Schnaar, 2001). Thus, MAG-gangliosides interactions promote axon myelin stability (Schnaar, 2010).

Gangliosides synthesis and complexity, in terms of sialic acid content, increase during brain development and myelin formation, particularly from the late human foetal growth to the first 2 years after birth. Really, myelin is not very enriched in gangliosides (Schmitt et al., 2015); rather they are characteristic components of neuron plasma membrane, particularly GM1, GD1a, GD1b and GT1b. The role of gangliosides in myelination is mainly associated with their ability to establish and modulate glia axon connections and MAGganglioside downstream signalling (Schmitt et al., 2015).

On the contrary of gangliosides, galactolipids, that is GalCer and sulphatides with long fatty acid chains (24:0 and 24:1), are abundant components of the myelin sheath. They are implicated in oligodendrocyte differentiation, myelin formation and stability (Dupree, Suzuki, \& Popko, 1998; Hirahara, Bansal, Honke, Ikenaka, \& Wada, 2004). Genetically engineered mice which do not express the enzyme UDP-galactose:ceramide galactosyltransferase forming GalCer, synthetize myelin replacing GalCer with GlcCer, but demonstrating tremoring, ataxia, nerve conduction deficits and progressive paralysis (Coetzee et al., 1996). Gathering evidences seem to suggest that galactolipids are not so crucial for myelin synthesis as they can be replaced by other lipid species, rather they are important for myelin stabilization through the multiple interactions that they can establish (Schmitt et al., 2015).

\section{5 | CONCLUSIONS AND PERSPECTIVES}

Sphingolipid and sphingoid molecules are not only abundant structural components of nervous cell plasma membranes and myelin, but are also intrinsically involved in nervous system development, in myelination and in myelin stability (Figure 2). Their ability to establish connections with other molecules such as proteins, as seen for MAG and gangliosides (Vyas \& Schnaar, 2001), or to modulate signalling strongly interconnected with cell survival such as S1P and Cer explains their importance for the maintenance of myelin sheath. Really, during myelination, the impossibility to synthetize specific sphingolipids does not impair the entire process, as missing species 


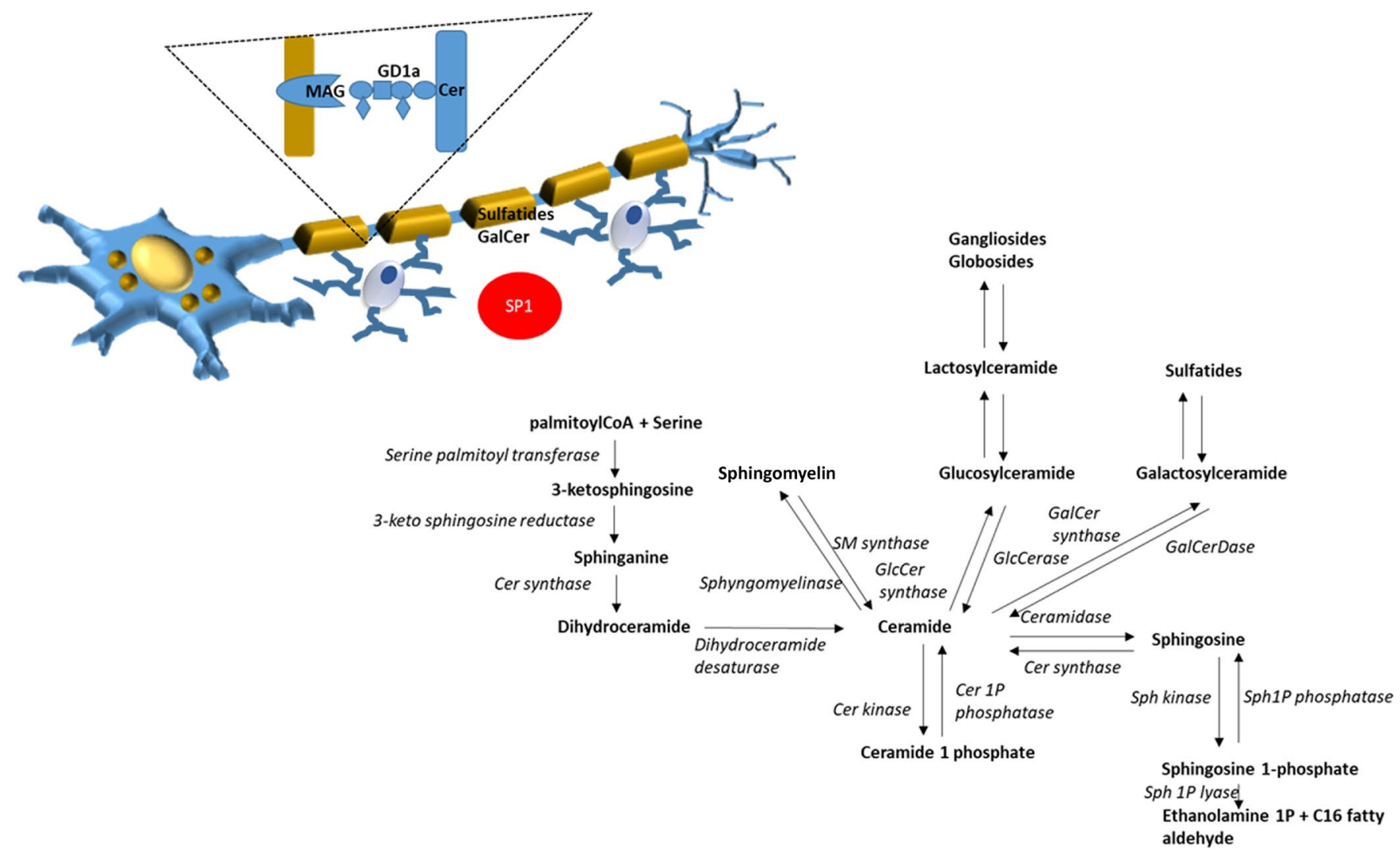

FIGURE 2 Overview of sphingoid and sphingolipid metabolism and correlation with myelin formation and stability

are replaced with other lipids belonging to the same family (Coetzee et al., 1996), yet myelin stability is not being kept and thus related symptoms appear early on. Sphingolipid and sphingoid alterations have been described in demyelinating disorders. In children's metabolic diseases, they are closely related to genetic defects affecting enzymes involved in sphingolipid metabolism, mostly inherited autosomal-recessively. Even if ever-increasing evidence indicates that so-called secondary sphingolipid modifications can arise and modify signalling and cell homeostasis (Prinetti et al., 2011), in MS, the direct cause of sphingolipid alterations remains obscure. Nevertheless, their role within demyelination and within the progressive phenotype of the disease is well established. In that light, some clinical similitudes among MS and some sphingolipidoses that also lead to misdiagnosis in children acquire a singular importance, and, above all, results emerging from genetic studies. Sphingolipidoses are considered rare diseases, but the frequency of heterozygote mutant variants is not negligible. It remains to define if variants identified in MS are the same involved in sphingolipidoses. Undoubtedly, these findings can help to better understand MS and its clinical features and progression, possibly identifying different targets and therapeutic approaches, considering mired therapy as novel and nearer possibility for the future.

\section{ACKNOWLEDGEMENTS}

This study was supported by Piano di sostegno alla ricerca BIOMETRA-Linea B (grant PSR2018_Giussani) to PG and Piano di sostegno alla ricerca BIOMETRA-Linea B (grant PSR2018_Tringali) to $\mathrm{CT}$.

\section{CONFLICT OF INTEREST}

AP is editor for the Journal of Neurochemistry and AP and PG are Members of the International Society for Neurochemistry.

\section{ORCID}

Paola Giussani (iD https://orcid.org/0000-0002-7793-1757

Alessandro Prinetti iD https://orcid.org/0000-0003-0252-2593

Cristina Tringali iD https://orcid.org/0000-0002-0632-6197

\section{REFERENCES}

Arnon, R., Crisp, E., Kelley, R., Ellison, G. W., Myers, L. W., \& Tourtellotte, W. W. (1980). Anti-ganglioside antibodies in multiple sclerosis. Journal of the Neurological Sciences, 46, 179-186.

Askari, V. R., Baradaran Rahimi, V., Tabatabaee, S. A., \& Shafiee-Nick, R. (2019). Combination of Imipramine, a sphingomyelinase inhibitor, and $\beta$-caryophyllene improve their therapeutic effects on experimental autoimmune encephalomyelitis (EAE). International Immunopharmacology, 77, 105923.

Australia and New Zealand Multiple Sclerosis Genetics Consortium (ANZgene). (2009). Genome-wide association study identifies new multiple sclerosis susceptibility loci on chromosomes 12 and 20. Nature Genetics, 41, 824-828.

Baranzini, S. E., Galwey, N. W., Wang, J., Khankhanian, P., Lindberg, R., Pelletier, D., ... Barnes, M. R. (2009). Pathway and network-based 
analysis of genome-wide association studies in multiple sclerosis. Human Molecular Genetics, 18, 2078-2090.

Baranzini, S. E., \& Oksenberg, J. R. (2017). The genetics of multiple sclerosis: From 0 to 200 in 50 Years. Trends in Genetics, 33, 960-970.

Baranzini, S. E., Srinivasan, R., Khankhanian, P., Okuda, D. T., Nelson, S. J., Matthews, P. M., ... Pelletier, D. (2010). Genetic variation influences glutamate concentrations in brains of patients with multiple sclerosis. Brain, 133, 2603-2611.

Baronica, K. B., Mlinac, K., Ozretić, D., Vladić, A., \& Bognar, S. K. (2011). Arylsulfatase a gene polymorphisms in relapsing remitting multiple sclerosis: Genotype-phenotype correlation and estimation of disease progression. Coll Antropol, 35(Suppl 1), 11-16.

Becker, K. A., Halmer, R., Davies, L., Henry, B. D., Ziobro-Henry, R., Decker, Y., ... Walter, S. (2017). Blockade of experimental multiple sclerosis by inhibition of the acid sphingomyelinase/ceramide system. Neurosignals, 25, 88-97.

Beecham, A. H., Patsopoulos, N. A., Xifara, D. K., Davis, M. F., Kemppinen, A., Cotsapas, C., ... McCauley, J. L. (2013). Analysis of immune-related loci identifies 48 new susceptibility variants for multiple sclerosis. Nature Genetics, 45, 1353-1360.

Bigaud, M., Guerini, D., Billich, A., Bassilana, F., \& Brinkmann, V. (2014). Second generation S1P pathway modulators: Research strategies and clinical developments. Biochimica Et Biophysica Acta, 1841, 745758. https://doi.org/10.1016/j.bbalip.2013.11.001

Chami, M., Halmer, R., Schnoeder, L., Anne Becker, K., Meier, C., Fassbender, K., ... Walter, S. (2017). Acid sphingomyelinase deficiency enhances myelin repair after acute and chronic demyelination. PLoS One, 12, e0178622. https://doi.org/10.1371/journ al.pone.0178622

Chebel, S., Barboura, I., Boughammoura-Bouatay, A., Ammar, M., Ferchichi, S., Miled, A., \& Frih-Ayed, M. (2009). Adult-type metachromatic leukodystrophy mimicking multiple sclerosis. Canadian Journal of Neurological Sciences, 36, 521-523. https://doi.org/10.1017/S0317 167100007940

Chudakova, D. A., Zeidan, Y. H., Wheeler, B. W., Yu, J., Novgorodov, S. A., Kindy, M. S., ... Gudz, T. I. (2008). Integrin-associated Lyn kinase promotes cell survival by suppressing acid sphingomyelinase activity. The Journal of Biological Chemistry, 283, 28806-28816. https://doi. org/10.1074/jbc.M803301200

Chun, J., \& Hartung, H. P. (2010). Mechanism of action of oral fingolimod (FTY720) in multiple sclerosis. Clinical Neuropharmacology, 33, 91-101. https://doi.org/10.1097/WNF.0b013e3181cbf825

Clarke, B. A., Majumder, S., Zhu, H., Lee, Y. T., Kono, M., Li, C., ... Proia, R. L. (2019). The Ormdl genes regulate the sphingolipid synthesis pathway to ensure proper myelination and neurologic function in mice. Elife, 8, e51067. https://doi.org/10.7554/eLife.51067

Cleland, W. W., \& Kennedy, E. P. (1960). The enzymatic synthesis of psychosine. Journal of Biological Chemistry, 235, 45-51.

Coelho, R. P., Payne, S. G., Bittman, R., Spiegel, S., \& Sato-Bigbee, C. (2007). The immunomodulator FTY720 has a direct cytoprotective effect in oligodendrocyte progenitors. Journal of Pharmacology and Experimental Therapeutics, 323, 626-635. https://doi.org/10.1124/ jpet.107.123927

Coelho, R. P., Saini, H. S., \& Sato-Bigbee, C. (2010). Sphingosine1-phosphate and oligodendrocytes: From cell development to the treatment of multiple sclerosis. Prostaglandins \& Other Lipid Mediators, 91, 139-144. https://doi.org/10.1016/j.prostaglan dins.2009.04.002

Coetzee, T., Fujita, N., Dupree, J., Shi, R., Blight, A., Suzuki, K., ... Popko, B. (1996). Myelination in the absence of galactocerebroside and sulfatide: Normal structure with abnormal function and regional instability. Cell, 86, 209-219. https://doi.org/10.1016/S0092 $-8674(00) 80093-8$

Colomba, P., Zizzo, C., Alessandro, R., Cammarata, G., Scalia, S., Giordano, A., ... Duro, G. (2018). Fabry disease and multiple sclerosis misdiagnosis: The role of family history and neurological signs. Oncotarget, 9, 7758-7762. https://doi.org/10.18632/oncot arget. 23970

Compston, A., \& Coles, A. (2002). Multiple sclerosis. Lancet, 359, 12211231. https://doi.org/10.1016/S0140-6736(02)08220-X

Cumings, J. N., \& Goodwin, H. (1968). Sphingolopids and phospholipids of myelin in multiple sclerosis. Lancet, 2, 664-665.

D'Auria, L., Reiter, C., Ward, E., Moyano, A. L., Marshall, M. S., Nguyen, D., ... Bongarzone, E. R. (2017). Psychosine enhances the shedding of membrane microvesicles: Implications in demyelination in Krabbe's disease. PLoS One, 12, e0178103. https://doi.org/10.1371/journ al.pone. 0178103

Dasgupta, S., \& Ray, S. K. (2017). Diverse biological functions of Sphingolipids in the CNS: Ceramide and sphingosine regulate myelination in developing brain but stimulate demyelination during pathogenesis of multiple sclerosis. Journal of Neurology and Psychology, 5. https://doi.org/10.13188/2332-3469.1000035

De Jager, P. L., Jia, X., Wang, J., de Bakker, P. I. W., Ottoboni, L., Aggarwal, N. T., ... Oksenberg, J. R. (2009). Meta-analysis of genome scans and replication identify CD6, IRF8 and TNFRSF1A as new multiple sclerosis susceptibility loci. Nature Genetics, 41, 776-782. https://doi. org/10.1038/ng.401

Dobson, R., \& Giovannoni, G. (2019). Multiple sclerosis - a review. European Journal of Neurology, 26, 27-40. https://doi.org/10.1111/ ene.13819

Dukala, D. E., \& Soliven, B. (2016). S1P1 deletion in oligodendroglial lineage cells: Effect on differentiation and myelination. Glia, 64, 570-582.

Dunn, T. M., Tifft, C. J., \& Proia, R. L. (2019). A perilous path: The inborn errors of sphingolipid metabolism. Journal of Lipid Research, 60, 475-483. https://doi.org/10.1194/jlr.S091827

Dupree, J. L., Suzuki, K., \& Popko, B. (1998). Galactolipids in the formation and function of the myelin sheath. Microscopy Research and Technique, 41, 431-440. https://doi.org/10.1002/(SICI)10970029(19980601)41:5;<431:AID-JEMT9;=3.0.CO;2-S

Dyment, D. A., Sadovnick, A. D., \& Ebers, G. C. (1997). Genetics of multiple sclerosis. Human Molecular Genetics, 6, 1693-1698.

Giri, S., Khan, M., Rattan, R., Singh, I., \& Singh, A. K. (2006). Krabbe disease: Psychosine-mediated activation of phospholipase A2 in oligodendrocyte cell death. Journal of Lipid Research, 47, 1478-1492. https://doi.org/10.1194/jlr.M600084-JLR200

Giussani, P., Tringali, C., Riboni, L., Viani, P., \& Venerando, B. (2014). Sphingolipids: Key regulators of apoptosis and pivotal players in cancer drug resistance. International Journal of Molecular Sciences, 15, 4356-4392. https://doi.org/10.3390/ijms15034356

Grassi, S., Chiricozzi, E., Mauri, L., Sonnino, S., \& Prinetti, A. (2019). Sphingolipids and neuronal degeneration in lysosomal storage disorders. Journal of Neurochemistry, 148, 600-611.

Grassi, S., Giussani, P., Mauri, L., Prioni, S., Sonnino, S., \& Prinetti, A. (2020). Lipid rafts and neurodegeneration: Structural and functional roles in physiologic aging and neurodegenerative diseases. Journal of Lipid Research, 61, 636-654. https://doi.org/10.1194/jlr.TR119 000427

Grassi, S., Mauri, L., Prioni, S., Cabitta, L., Sonnino, S., Prinetti, A., \& Giussani, P. (2019). Sphingosine 1-phosphate receptors and metabolic enzymes as druggable targets for brain diseases. Frontiers in Pharmacology, 10, 807. https://doi.org/10.3389/ fphar.2019.00807

Haghighi, S., Lekman, A., Nilsson, S., Blomqvist, M., \& Andersen, O. (2012). Myelin glycosphingolipid immunoreactivity and CSF levels in multiple sclerosis. Acta Neurologica Scandinavica, 125, 64-70. https:// doi.org/10.1111/j.1600-0404.2011.01554.x

Haghighi, S., Lekman, A., Nilsson, S., Blomqvist, M., \& Andersen, O. (2013). Increased CSF sulfatide levels and serum glycosphingolipid antibody levels in healthy siblings of multiple sclerosis patients. Journal 
of the Neurological Sciences, 326, 35-39. https://doi.org/10.1016/j. jns.2013.01.007

Halder, R. C., Jahng, A., Maricic, I., \& Kumar, V. (2007). Mini review: Immune response to myelin-derived sulfatide and CNSdemyelination. Neurochemical Research, 32, 257-262. https://doi. org/10.1007/s11064-006-9145-4

Halmer, R., Walter, S., \& Faßbender, K. (2014). Sphingolipids: Important players in multiple sclerosis. Cellular Physiology and Biochemistry, 34, 111-118. https://doi.org/10.1159/000362988

Hannun, Y. A., \& Bell, R. M. (1989). Regulation of protein kinase C by sphingosine and lysosphingolipids. Clinica Chimica Acta, 185, 333345. https://doi.org/10.1016/0009-8981(89)90224-6

Herz, B., \& Bach, G. (1984). Arylsulfatase A in pseudodeficiency. Human Genetics, 66, 147-150. https://doi.org/10.1007/BF00286589

Hill, C. H., Cook, G. M., Spratley, S. J., Fawke, S., Graham, S. C., \& Deane, J. E. (2018). The mechanism of glycosphingolipid degradation revealed by a GALC-SapA complex structure. Nature Communications, 9, 151. https://doi.org/10.1038/s41467-017-02361-y

Hirahara, Y., Bansal, R., Honke, K., Ikenaka, K., \& Wada, Y. (2004). Sulfatide is a negative regulator of oligodendrocyte differentiation: Development in sulfatide-null mice. Glia, 45, 269-277. https://doi. org/10.1002/glia.10327

Hussain, G., Wang, J., Rasul, A., Anwar, H., Imran, A., Qasim, M., ... Sun, T. (2019). Role of cholesterol and sphingolipids in brain development and neurological diseases. Lipids in Health and Disease, 18, 26. https:// doi.org/10.1186/s12944-019-0965-z

Igisu, H., \& Suzuki, K. (1984). Progressive accumulation of toxic metabolite in a genetic leukodystrophy. Science, 224, 753-755. https://doi. org/10.1126/science.6719111

Ilyas, A. A., Chen, Z. W., \& Cook, S. D. (2003). Antibodies to sulfatide in cerebrospinal fluid of patients with multiple sclerosis. Journal of Neuroimmunology, 139, 76-80. https://doi.org/10.1016/S0165 $-5728(03) 00131-0$

Indellicato, R., \& Trinchera, M. (2019). The link between gaucher disease and Parkinson's disease sheds light on old and novel disorders of sphingolipid metabolism. International Journal of Molecular Sciences, 20. https://doi.org/10.3390/ijms20133304

International Multiple Sclerosis Genetics Consortium. (2018). Lowfrequency and rare-coding variation contributes to multiple sclerosis risk. Cell 175, 1679-1687. e1677.

Ishibashi, T., Dupree, J. L., Ikenaka, K., Hirahara, Y., Honke, K., Peles, E., ... Baba, H. (2002). A myelin galactolipid, sulfatide, is essential for maintenance of ion channels on myelinated axon but not essential for initial cluster formation. Journal of Neuroscience, 22, 6507-6514. https://doi.org/10.1523/JNEUROSCI.22-15-06507.2002

Jakkula, E., Leppä, V., Sulonen, A.-M., Varilo, T., Kallio, S., Kemppinen, A., ... Peltonen, L. (2010). Genome-wide association study in a highrisk isolate for multiple sclerosis reveals associated variants in STAT3 gene. American Journal of Human Genetics, 86, 285-291. https://doi. org/10.1016/j.ajhg.2010.01.017

Jana, A., \& Pahan, K. (2010). Sphingolipids in multiple sclerosis. NeuroMolecular Medicine, 12, 351-361. https://doi.org/10.1007/ s12017-010-8128-4

Jeon, S. B., Yoon, H. J., Park, S. H., Kim, I. H., \& Park, E. J. (2008). Sulfatide, a major lipid component of myelin sheath, activates inflammatory responses as an endogenous stimulator in brain-resident immune cells. The Journal of Immunology, 181, 8077-8087. https://doi. org/10.4049/jimmunol.181.11.8077

Jung, C. G., Kim, H. J., Miron, V. E., Cook, S., Kennedy, T. E., Foster, C. A., ... Soliven, B. (2007). Functional consequences of S1P receptor modulation in rat oligodendroglial lineage cells. Glia, 55, 1656-1667. https://doi.org/10.1002/glia.20576

Kanter, J. L., Narayana, S., Ho, P. P., Catz, I., Warren, K. G., Sobel, R. A., ... Robinson, W. H. (2006). Lipid microarrays identify key mediators of autoimmune brain inflammation. Nature Medicine, 12, 138-143. https://doi.org/10.1038/nm1344

Kappler, J., Pötter, W., Gieselmann, V., Kiessling, W., Friedl, W., \& Propping, P. (1991). Phenotypic consequences of low arylsulfatase A genotypes (ASAp/ASAp and ASA-/ASAp): Does there exist an association with multiple sclerosis? Developmental Neuroscience, 13, 228-231.

Kasai, N., Pachner, A. R., \& Yu, R. K. (1986). Anti-glycolipid antibodies and their immune complexes in multiple sclerosis. Journal of the Neurological Sciences, 75, 33-42. https://doi.org/10.1016/0022510X(86)90048-1

Kim, H. J., Miron, V. E., Dukala, D., Proia, R. L., Ludwin, S. K., Traka, M., ... Soliven, B. (2011). Neurobiological effects of sphingosine 1-phosphate receptor modulation in the cuprizone model. The FASEB Journal, 25, 1509-1518. https://doi.org/10.1096/fj.10-173203

Lamari, F., Mochel, F., Sedel, F., \& Saudubray, J. M. (2013). Disorders of phospholipids, sphingolipids and fatty acids biosynthesis: Toward a new category of inherited metabolic diseases. Journal of Inherited Metabolic Disease, 36, 411-425. https://doi.org/10.1007/s1054 5-012-9509-7

Laquerriere, A., Bekri, S., Suzuki, K., \& Harding, B. N. (2018) Sphingolipidoses and Related Disorders. Developmental Neuropathology, Second Edition. Edited by Homa Adle-Biassette, Brian N. Harding, and Jeffrey A. Golden, 313-367.

Lassmann, H. (2018). Multiple sclerosis pathology. Cold Spring Harbor Perspectives in Medicine, 8, a028936. https://doi.org/10.1101/cshpe rspect.a028936

Leurs, C. E., Lopes Pinheiro, M. A., Wierts, L., den Hoedt, S., Mulder, M. T., Eijlers, A., ... de Vries, H. E. (2019). Acid sphingomyelinase: No potential as a biomarker for multiple sclerosis. Multiple Sclerosis and Related Disorders, 28, 44-49. https://doi.org/10.1016/j. msard.2018.11.024

Li, Y., Xu, Y., Benitez, B. A., Nagree, M. S., Dearborn, J. T., Jiang, X., ... Sands, M. S. (2019). Genetic ablation of acid ceramidase in Krabbe disease confirms the psychosine hypothesis and identifies a new therapeutic target. Proceedings of the National Academy of Sciences, 116, 20097-20103. https://doi.org/10.1073/pnas.1912108116

Lombardi, M., Parolisi, R., Scaroni, F., Bonfanti, E., Gualerzi, A., Gabrielli, M., ... Verderio, C. (2019). Detrimental and protective action of microglial extracellular vesicles on myelin lesions: Astrocyte involvement in remyelination failure. Acta Neuropathologica. https://doi. org/10.1007/s00401-019-02049-1

Marbois, B. N., Faull, K. F., Fluharty, A. L., Raval-Fernandes, S., \& Rome, L. H. (2000). Analysis of sulfatide from rat cerebellum and multiple sclerosis white matter by negative ion electrospray mass spectrometry. Biochimica Et Biophysica Acta, 1484, 59-70. https://doi.org/10.1016/ S1388-1981(99)00201-2

Marconi, S., Acler, M., Lovato, L., De Toni, L., Tedeschi, E., Anghileri, E., ... Bonetti, B. (2006). Anti-GD2-like IgM autoreactivity in multiple sclerosis patients. Multiple Sclerosis Journal, 12, 302-308. https://doi. org/10.1191/135248506ms1279oa

Maricic, I., Halder, R., Bischof, F., \& Kumar, V. (2014). Dendritic cells and anergic type I NKT cells play a crucial role in sulfatide-mediated immune regulation in experimental autoimmune encephalomyelitis. The Journal of Immunology, 193, 1035-1046. https://doi.org/10.4049/ jimmunol.1302898

Marshall, M. S., \& Bongarzone, E. R. (2016). Beyond Krabbe's disease: The potential contribution of galactosylceramidase deficiency to neuronal vulnerability in late-onset synucleinopathies. Journal of Neuroscience Research, 94, 1328-1332.

Martinelli-Boneschi, F., Esposito, F., Brambilla, P., Lindström, E., Lavorgna, G., Stankovich, J., ... Comi, G. (2012). A genome-wide association study in progressive multiple sclerosis. Multiple Sclerosis Journal, 18, 1384-1394. https://doi.org/10.1177/1352458512439118 
Matà, S., Lolli, F., Söderström, M., Pinto, F., \& Link, H. (1999). Multiple sclerosis is associated with enhanced $B$ cell responses to the ganglioside GD1a. Multiple Sclerosis, 5, 379-388. https://doi.org/10.1191/13524 5899678846483

Mayo, L., Trauger, S. A., Blain, M., Nadeau, M., Patel, B., Alvarez, J. I., ... Quintana, F. J. (2014). Regulation of astrocyte activation by glycolipids drives chronic CNS inflammation. Nature Medicine, 20, 11471156. https://doi.org/10.1038/nm.3681

McGonigal, R., Barrie, J. A., Yao, D., McLaughlin, M., Cunningham, M. E., Rowan, E. G., \& Willison, H. J. (2019). Glial sulfatides and neuronal complex Gangliosides are functionally interdependent in maintaining myelinating axon integrity. Journal of Neuroscience, 39, 63-77.

McKeown, S. R., \& Allen, I. V. (1979). The fragility of cerebral lysosomes in multiple sclerosis. Neuropathology and Applied Neurobiology, 5, 405-415.

Merrill, A. H. Jr (2011). Sphingolipid and glycosphingolipid metabolic pathways in the era of sphingolipidomics. Chemical Reviews, 111, 6387-6422.

Migdalska-Richards, A., \& Schapira, A. H. (2016). The relationship between glucocerebrosidase mutations and Parkinson disease. Journal of Neurochemistry, 139(Suppl 1), 77-90.

Miron, V. E., Hall, J. A., Kennedy, T. E., Soliven, B., \& Antel, J. P. (2008). Cyclical and dose-dependent responses of adult human mature oligodendrocytes to fingolimod. American Journal of Pathology, 173, 1143-1152.

Miron, V. E., Jung, C. G., Kim, H. J., Kennedy, T. E., Soliven, B., \& Antel, J. P. (2008). FTY720 modulates human oligodendrocyte progenitor process extension and survival. Annals of Neurology, 63, 61-71.

Moscatelli, E. A., \& Isaacson, E. (1969). Gas liquid chromatographic analysis of sphingosine bases in sphingolipids of human normal and multiple sclerosis cerebral white matter. Lipids, 4, 550-555.

Moyano, A. L., Pituch, K., Li, G., van Breemen, R., Mansson, J. E., \& Givogri, M. I. (2013). Levels of plasma sulfatides C18: 0 and C24: 1 correlate with disease status in relapsing-remitting multiple sclerosis. Journal of Neurochemistry, 127, 600-604.

Mycko, M. P., Sliwinska, B., Cichalewska, M., Cwiklinska, H., Raine, C. S., \& Selmaj, K. W. (2014). Brain glycolipids suppress T helper cells and inhibit autoimmune demyelination. Journal of Neuroscience, 34 , 8646-8658.

Olsen, A. S. B., \& Færgeman, N. J. (2017). Sphingolipids: Membrane microdomains in brain development, function and neurological diseases. Open Biol, 7, 170069. https://doi.org/10.1098/rsob.170069

Patsopoulos, N. A., Esposito, F., Reischl, J. et al (2011). Genome-wide meta-analysis identifies novel multiple sclerosis susceptibility loci. Annals of Neurology, 70, 897-912. https://doi.org/10.1002/ ana.22609

Pender, M. P., Csurhes, P. A., Wolfe, N. P., Hooper, K. D., Good, M. F., McCombe, P. A., \& Greer, J. M. (2003). Increased circulating T cell reactivity to GM3 and GQ1b gangliosides in primary progressive multiple sclerosis. Journal of Clinical Neuroscience, 10, 63-66. https:// doi.org/10.1016/S0967-5868(02)00270-9

Pieragostino, D., Cicalini, I., Lanuti, P., Ercolino, E., di loia, M., Zucchelli, M., ... Del Boccio, P. (2018). Enhanced release of acid sphingomyelinase-enriched exosomes generates a lipidomics signature in CSF of Multiple Sclerosis patients. Scientific Reports, 8, 3071. https://doi. org/10.1038/s41598-018-21497-5

Podbielska, M., \& Hogan, E. L. (2009). Molecular and immunogenic features of myelin lipids: Incitants or modulators of multiple sclerosis? Multiple Sclerosis Journal, 15, 1011-1029. https://doi. org/10.1177/1352458509106708

Potter, G. B., Santos, M., Davisson, M. T., Rowitch, D. H., Marks, D. L., Bongarzone, E. R., \& Petryniak, M. A. (2013). Missense mutation in mouse GALC mimics human gene defect and offers new insights into Krabbe disease. Human Molecular Genetics, 22, 3397-3414. https:// doi.org/10.1093/hmg/ddt190
Prinetti, A., Prioni, S., Chiricozzi, E., Schuchman, E. H., Chigorno, V., \& Sonnino, S. (2011). Secondary alterations of sphingolipid metabolism in lysosomal storage diseases. Neurochemical Research, 36, 16541668. https://doi.org/10.1007/s11064-010-0380-3

Pyne, N. J., \& Pyne, S. (2017). Sphingosine 1-phosphate receptor 1 signaling in mammalian cells. Molecules, 22. https://doi.org/10.3390/molec ules22030344

Saini, H. S., Coelho, R. P., Goparaju, S. K., Jolly, P. S., Maceyka, M., Spiegel, S., \& Sato-Bigbee, C. (2005). Novel role of sphingosine kinase 1 as a mediator of neurotrophin-3 action in oligodendrocyte progenitors. Journal of Neurochemistry, 95, 1298-1310. https://doi. org/10.1111/j.1471-4159.2005.03451.x

Sawcer, S., Franklin, R. J., \& Ban, M. (2014). Multiple sclerosis genetics. The Lancet Neurology, 13, 700-709. https://doi.org/10.1016/S1474 -4422(14)70041-9

Sawcer, S., Hellenthal, G., Pirinen, M., Spencer, C. C. A., Patsopoulos, N. A., Moutsianas, L., ... Compston, A. (2011). Genetic risk and a primary role for cell-mediated immune mechanisms in multiple sclerosis. Nature, 476, 214-219.

Schmitt, S., Castelvetri, L. C., \& Simons, M. (2015). Metabolism and functions of lipids in myelin. Biochimica Et Biophysica Acta, 1851, 9991005. https://doi.org/10.1016/j.bbalip.2014.12.016

Schnaar, R. L. (2010). Brain gangliosides in axon-myelin stability and axon regeneration. FEBS Letters, 584, 1741-1747. https://doi. org/10.1016/j.febslet.2009.10.011

Schuchman, E. H. (2007). The pathogenesis and treatment of acid sphingomyelinase-deficient Niemann-Pick disease. Journal of Inherited Metabolic Disease, 30, 654-663. https://doi.org/10.1007/s1054 5-007-0632-9

Scott-Hewitt, N. J., Folts, C. J., Hogestyn, J. M., Piester, G., MayerPröschel, M., \& Noble, M. D. (2017). Heterozygote galactocerebrosidase (GALC) mutants have reduced remyelination and impaired myelin debris clearance following demyelinating injury. Human Molecular Genetics, 26, 2825-2837. https://doi.org/10.1093/hmg/ $\mathrm{dd} \times 153$

Scott-Hewitt, N. J., Folts, C. J., \& Noble, M. D. (2018). Heterozygous carriers of galactocerebrosidase mutations that cause Krabbe disease have impaired microglial function and defective repair of myelin damage. Neural Regeneration Research, 13, 393-401. https://doi. org/10.4103/1673-5374.228712

Seyedsadr, M. S., Weinmann, O., Amorim, A., Ineichen, B. V., Egger, M., Mirnajafi-Zadeh, J., ... Schwab, M. E. (2019). Inactivation of sphingosine-1-phosphate receptor 2 (S1PR2) decreases demyelination and enhances remyelination in animal models of multiple sclerosis. Neurobiology of Diseases, 124, 189-201. https://doi.org/10.1016/j.nbd.2018.11.018

Singh, I., Pahan, K., Khan, M., \& Singh, A. K. (1998). Cytokine-mediated induction of ceramide production is redox-sensitive. Implications to proinflammatory cytokine-mediated apoptosis in demyelinating diseases. Journal of Biological Chemistry, 273, 20354-20362. https://doi. org/10.1074/jbc.273.32.20354

Spratley, S. J., Hill, C. H., Viuff, A. H., Edgar, J. R., Skjødt, K., \& Deane, J. E. (2016). Molecular mechanisms of disease pathogenesis differ in krabbe disease variants. Traffic, 17, 908-922. https://doi. org/10.1111/tra.12404

Takahashi, T., \& Suzuki, T. (2012). Role of sulfatide in normal and pathological cells and tissues. Journal of Lipid Research, 53, 1437-1450. https://doi.org/10.1194/jlr.R026682

Thompson, A. J., Baranzini, S. E., Geurts, J., Hemmer, B., \& Ciccarelli, O. (2018). Multiple sclerosis. Lancet, 391, 1622-1636. https://doi. org/10.1016/S0140-6736(18)30481-1

Traboulsee, A. L., Sadovnick, A. D., Encarnacion, M., Bernales, C. Q., Yee, I. M., Criscuoli, M. G., \& Vilariño-Güell, C. (2017). Common genetic etiology between "multiple sclerosis-like" single-gene disorders and familial multiple sclerosis. Human Genetics, 136, 705-714. https://doi. org/10.1007/s00439-017-1784-9 
Vanderver, A., Hussey, H., Schmidt, J. L., Pastor, W., \& Hoffman, H. J. (2012). Relative incidence of inherited white matter disorders in childhood to acquired pediatric demyelinating disorders. Seminars in Pediatric Neurology, 19, 219-223. https://doi.org/10.1016/j. spen.2012.10.001

Vidaurre, O. G., Haines, J. D., Katz Sand, I., Adula, K. P., Huynh, J. L., McGraw, C. A., ... Casaccia, P. (2014). Cerebrospinal fluid ceramides from patients with multiple sclerosis impair neuronal bioenergetics. Brain, 137, 2271-2286. https://doi.org/10.1093/brain/awu139

Vyas, A. A., Patel, H. V., Fromholt, S. E., Heffer-Lauc, M., Vyas, K. A., Dang, J., ... Schnaar, R. L. (2002). Gangliosides are functional nerve cell ligands for myelin-associated glycoprotein (MAG), an inhibitor of nerve regeneration. Proceedings of the National Academy of Sciences, 99, 8412-8417. https://doi.org/10.1073/pnas.072211699

Vyas, A. A., \& Schnaar, R. L. (2001). Brain gangliosides: Functional ligands for myelin stability and the control of nerve regeneration. Biochimie, 83, 677-682. https://doi.org/10.1016/S0300-9084(01)01308-6

Walkley, S. U. (2004). Secondary accumulation of gangliosides in lysosomal storage disorders. Seminars in Cell \& Developmental Biology, 15, 433-444. https://doi.org/10.1016/j.semcdb.2004.03.002

Walter, S., Gulbins, E., Halmer, R., Jahromi, N. H., Becker, K. A., Schottek, A., \& Fassbender, K. (2019). Pharmacological inhibition of acid sphingomyelinase ameliorates experimental autoimmune encephalomyelitis. Neurosignals, 27, 20-31.

Wattenberg, B. W. (2019). Intra- and intercellular trafficking in sphingolipid metabolism in myelination. Advances in Biological Regulation, 71, 97-103. https://doi.org/10.1016/j.jbior.2018.11.002

Watzlawik, J. O., Warrington, A. E., \& Rodriguez, M. (2013). PDGF is required for remyelination-promoting IgM stimulation of oligodendrocyte progenitor cell proliferation. PLoS One, 8, e55149. https://doi. org/10.1371/journal.pone.0055149

Weisfeld-Adams, J. D., Katz Sand, I. B., Honce, J. M., \& Lublin, F. D. (2015). Differential diagnosis of Mendelian and mitochondrial disorders in patients with suspected multiple sclerosis. Brain, 138, 517539. https://doi.org/10.1093/brain/awu397

Wheeler, D., Bandaru, V. V., Calabresi, P. A., Nath, A., \& Haughey, N. J. (2008). A defect of sphingolipid metabolism modifies the properties of normal appearing white matter in multiple sclerosis. Brain, 131, 3092-3102. https://doi.org/10.1093/brain/awn190

White, A. B., Givogri, M. I., Lopez-Rosas, A., Cao, H., van Breemen, R., Thinakaran, G., \& Bongarzone, E. R. (2009). Psychosine accumulates in membrane microdomains in the brain of krabbe patients, disrupting the raft architecture. Journal of Neuroscience, 29, 6068-6077. https://doi.org/10.1523/JNEUROSCI.5597-08.2009

Yahara, S., Kawamura, N., Kishimoto, Y., Saida, T., \& Tourtellotte, W. W. (1982). A change in the cerebrosides and sulfatides in a demyelinating nervous system. Development of the methodology and study of multiple sclerosis and Wallerian degeneration. Journal of the Neurological Sciences, 54, 303-315. https://doi.org/10.1016/0022510X(82)90191-5

Yau, W. Y., Fabis-Pedrini, M. J., \& Kermode, A. G. (2017). Fabry heterozygote mimicking multiple sclerosis. BMJ Case Reports. https://doi. org/10.1136/bcr-2017-220274

Zaprianova, E., Deleva, D., llinov, P., Sultanov, E., Filchev, A., Christova, L., \& Sultanov, B. (2001). Serum ganglioside patterns in multiple sclerosis. Neurochemical Research, 26, 95-100.

Zizioli, D., Guarienti, M., Tobia, C., Gariano, G., Borsani, G., Bresciani, R., ... Presta, M. (2014). Molecular cloning and knockdown of galactocerebrosidase in zebrafish: New insights into the pathogenesis of Krabbe's disease. Biochimica Et Biophysica Acta, 1842, 665-675. https://doi.org/10.1016/j.bbadis.2014.01.008

How to cite this article: Giussani P, Prinetti A, Tringali C. The role of Sphingolipids in myelination and myelin stability and their involvement in childhood and adult demyelinating disorders. J. Neurochem. 2020;00:1-12. https://doi. org/10.1111/jnc.15133 